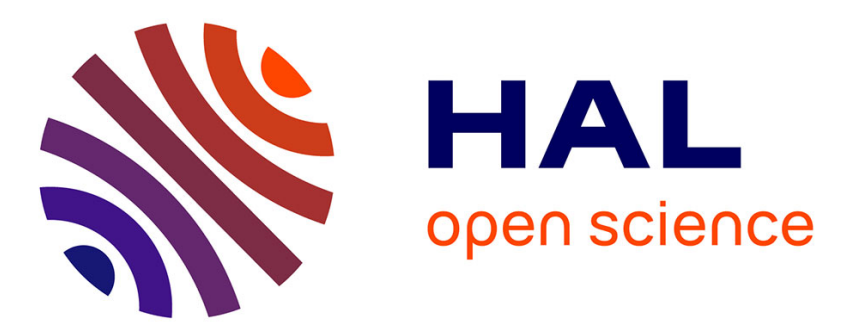

\title{
Grad-cryo-EM: Tool to Isolate Translation Initiation Complexes from Rabbit Reticulocyte Lysate Suitable for Structural Studies
}

Javier Rol-Moreno, Lauriane Kuhn, Stefano Marzi, Angelita Simonetti

\section{- To cite this version:}

Javier Rol-Moreno, Lauriane Kuhn, Stefano Marzi, Angelita Simonetti. Grad-cryo-EM: Tool to Isolate Translation Initiation Complexes from Rabbit Reticulocyte Lysate Suitable for Structural Studies. Methods Mol Biol, pp.329-339, 2020, 10.1007/978-1-0716-0278-2_21 . hal-02966098

\section{HAL Id: hal-02966098 \\ https://hal.science/hal-02966098}

Submitted on 17 Nov 2020

HAL is a multi-disciplinary open access archive for the deposit and dissemination of scientific research documents, whether they are published or not. The documents may come from teaching and research institutions in France or abroad, or from public or private research centers.
L'archive ouverte pluridisciplinaire HAL, est destinée au dépôt et à la diffusion de documents scientifiques de niveau recherche, publiés ou non, émanant des établissements d'enseignement et de recherche français ou étrangers, des laboratoires publics ou privés. 


\section{Grad-CryoEM: tool to isolate Translation Initiation Complexes from rabbit reticulocyte lysate suitable for structural studies}

Javier Rol-Moreno', Lauriane Kuhn², Stefano Marzi ${ }^{1}$ and Angelita Simonetti ${ }^{1{ }^{*}}$

*Corresponding author: a.simonetti@ibmc-cnrs.unistra.fr

${ }^{1}$ Université de Strasbourg, CNRS, Architecture et Réactivité de l'ARN, UPR 9002, F-67000 Strasbourg, France.

${ }^{2}$ Plateforme protéomique Strasbourg Esplanade, CNRS, FR1589, F-67000 Strasbourg, France.

Key words: Translation Initiation, Native Ribosome Complexes, Cryo-Electron Microscopy, Mass Spectrometry. 


\begin{abstract}
Since its development, single-particle cryogenic electron microscopy (cryo-EM) has played a central role in the study at medium resolution of both bacterial and eukaryotic ribosomal complexes. With the advent of the direct electron detectors and new processing software which allow obtaining structures at atomic resolution, formerly obtained only by X-ray crystallography, Cryo-EM has become the method of choice for the structural analysis of the translation machinery. In most of the cases, the ribosomal complexes at different stages of the translation process are assembled in vitro from purified components, which limit the analysis to previously well characterized complexes with known factors composition. The initiation phase of the protein synthesis is a very dynamic process during which several proteins interact with the translation apparatus leading to the formation of a chronological series of Initiation Complexes (ICs). Here we describe a method to isolate ICs assembled on natural in vitro transcribed mRNA directly from rabbit reticulocyte lysate (RRL) by sucrose density gradient centrifugation. The Grad-CryoEM approach allows investigating structures and composition of intermediate ribosomal complexes prepared in near-native condition by Cryo-EM and mass spectrometry analyses. This is a powerful approach, which could be used to study translation initiation of any mRNAs, including IRES containing ones, and which could be adapted to different cell extracts.
\end{abstract}




\section{Introduction}

The ribosome ( $80 \mathrm{~S}$ particle in eukaryotes) is a dynamic molecular machine at the heart of the translation process, which is composed of a large and a small subunit (40S and 60S) made of ribosomal rRNA and proteins. Accompanied by several conformational changes and guided by a multitude of protein factors, the ribosome incorporates amino acids into proteins selecting aminoacylated tRNAs as specified by the mRNA codons. The active protein synthesis phase (translation elongation) is fast and accurate, and its mechanism is conserved though all organisms. In this phase, the ribosome incorporates up to 20 amino acids per second with a very low error rate [1-5]. The initiation phase is a much more sophisticated and slow process; the ribosome assembles on the mRNA in the order of seconds $[6,7]$. This long time is the result of a highly regulated process to careful search the start site, usually an AUG codon, along the mRNA molecule. For bulk protein synthesis, the mRNA start codon is found by a base-by-base

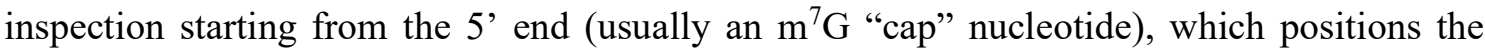
proximal AUG in the 40S subunit, a process that has been termed scanning. At least 13 initiation factors (eIFs) are required to ensure accurate AUG localization [8-11]. The first ribosomal initiation complex 43SIC, which is competent for mRNA $5^{\prime} \rightarrow 3^{\prime}$ scanning, is recruited on the cap and is composed of $40 \mathrm{~S}$ ribosomal subunit and several "core" factors: eIF2/Met-tRNAi ${ }^{\text {Met }}$, eIF1, eIF1A and eIF3. The scanning ends when the codon-anticodon interaction stabilizes a second ribosomal initiation complex, the $48 \mathrm{SIC}$ on the start codon. The third complex is the 80SIC, formed upon subunit joining and release of the initiation factors.

Several molecular aspects of the translation initiation process have been clarified by structural studies on in vitro reconstituted complexes with a limited set of purified factors and short non-biologically relevant mRNA mimicking fragments. Nevertheless, several "accessory" factors might be required depending on the structural and sequence features of the 
mRNAs [12] and their identity, roles and mechanisms still need to be discovered. Moreover, alternative mechanisms relying on specific mRNA structural features can escape this classical model. Two examples are provided by the translation initiation of IRES containing mRNAs and the tethering mechanism of histone $\mathrm{H} 4 \mathrm{mRNA}$. Internal ribosomal entry sites (IRES) characterizes a heterogeneous class of mechanisms used by some viral and cellular mRNAs to improve translation efficiency and escape global control. mRNA structures located at their 5' untranslated regions (5' UTRs), directly guide the ribosome on the start codon without scanning and with the involvement of only a partial set of eIFs, but sometimes requiring IRES-transacting factors (ITAFs) [9, 13-15]. Similarly to the IRES, also in the "ribosome tethering" the AUG is found directly without scanning thanks to two structural RNA elements which are located in the coding region of $\mathrm{H} 4 \mathrm{mRNA}[16,17]$.

These examples indicate how the eukaryotic translation initiation process is often mRNA-specific, depending on the presence of different signals. Furthermore, new initiation factors are continuously discovered which are involved in specific assembly processes. Therefore, the development of strategies allowing the structural analysis of complexes formed on natural mRNAs and isolated directly from cell extracts, without any a priori prejudice on the eIFs composition, would represent a remarkable advance to understand their specific translation initiation mechanisms.

The investigation of labile multi-factors translation initiation complexes represents a major challenge for a structural biologist. Single particle cryo-electron microscopy (Cryo-EM) technique had played a fundamental role in the structural study of the ribosome and of the process of translation initiation in both bacteria and eukaryotes. On the other hand, as ribosomes are bulky, electron dense, and distributing nicely on Cryo-EM grids, they are producing perfect images and have assisted the development of several image processing methods. Despite this 
happy connubium since the down of Cryo-EM in the early 80s [18], the first reconstructions of eukaryotic translation initiation complexes appeared only a little more than 10 years ago [19, 20]. More recently, several studies have clarified the action of factors involved in ribosome scanning and tRNA accommodation [21-23], and the localization of the huge factor platform eIF3 important for mRNA binding [24, 25]. These studies, focused mainly on the canonical cap-dependent mechanism, represent partial or pre-initiation in vitro assembled complexes. To obviate the need of studying native complexes by Cryo-EM, we have recently set up two specific protocols to isolate from rabbit reticulocyte lysates (RRL) ribosomal particles at different stages during initiation.

The first method $[26,27]$ allows purification of stable complexes, as the 80SICs, where no factors are bound. This method is based on mRNA ligation to a biotinylated oligo-DNA that is immobilized on streptavidin-coated magnetic beads and involves extensive salt washes. In this way, using a combination of cycloheximide/hygromycin to prevent the first translocation step, 80SIC formed on H4 mRNA was purified and its structure solved at $9.3 \AA[16]$, revealing how proper start codon positioning is achieved by a direct mRNA-rRNA interaction.

In this chapter, we provide a detailed protocol of the second method (Grad-CryoEM) developed to isolate stalled 48SICs assembled on natural in vitro transcribed mRNAs by sucrose density gradient centrifugation. Sucrose gradients are commonly used to profile ribosomes distribution on mRNA (polysomes) and the presence of specific inhibitors results in the accumulation of translation initiation intermediates, which sediment at the corresponding sucrose densities. Figure 1 shows the different radioactivity profiles on a $7 \%-47 \%$ sucrosegradient obtained by incubating radiolabelled $\beta$-globin mRNA with nuclease treated RRL in the absence of any inhibitor (blue line), or in the presence of cycloheximide (green line) or GMP-PNP (red line). While polysomes are detectable without any inhibitor, the addition of 
cycloheximide, inhibiting the eEF2-mediated translocation, blocks the progression of the translation to the elongation phase with the consequent accumulation of $80 \mathrm{~S}$ monomer ribosomes $[28,29]$. To block translation initiation before $60 \mathrm{~S}$ association, non-hydrolysable nucleotides can be used. When nuclease-treated RRL are supplemented with a nonhydrolysable analog of GTP (GMP-PNP) the assembling of the 48SIC on the mRNA of interest arrests after start codon recognition, prior to eIF2 dissociation and large ribosomal subunit joining $[30,31]$. These complexes can be easily isolated by centrifugation on appropriate sucrose gradients, which are both resolutive (even a 48SIC could be separated from 60S large ribosomal subunit) and gentle, preserving factors association. Composition of the isolated complexes will be then determined by mass spectrometry analysis, while their structure analyzed by Cryo-EM using a state-of-art framework (SCIPION [32]), allowing to sort out the structures of different complexes present in a single sample (based on Relion 3D classification [33] or Frealign ML classification [34]). This strategy is adaptable to study translation initiation on any mRNA of interest, including IRES containing ones, with any cell extract that can be made from different cell lines, tissues, plants, insects, etc.

\section{Materials}

\subsection{Cell extracts, buffers, solutions and reagents}

1. Rabbit Reticulocyte Lysate System, Nuclease Treated (L4960 - Promega).

2. TMSDT buffer: $40 \mathrm{mM}$ Tris- $\mathrm{HCl} \mathrm{pH} 8.1,22 \mathrm{mM} \mathrm{MgCl}_{2}, 5 \mathrm{mM}$ DTT (dithiothreitol), $0.01 \%$ Triton-X100, $1 \mathrm{mM}$ spermidine. This buffer is used for in vitro transcription.

3. RNA Elution Buffer: 0.5 $\mathrm{M} \mathrm{NH}_{4} \mathrm{OAc}$ pH 6.5, 0,1 \% Sodium Dodecyl Sulfate (SDS), 1 mM ethylenediaminetetraacetic acid (EDTA). 
4. Buffer A: 25 mM HEPES-KOH pH 7.6, 79 mM KOAc, $0.5 \mathrm{mM} \mathrm{Mg}(\mathrm{OAc})_{2}, 2$ mM DTT. This buffer is prepared as $5 \mathrm{X}$ stock solution and used to obtain sucrose solutions at different concentrations to make the gradients.

5. $60 \%$ sucrose stock solution. Dissolve $60 \mathrm{~g}$ of $\mathrm{D}(+)$-Saccharose (VWR International) in a total volume of $100 \mathrm{~mL}$ of ultrapure water. $60 \%$ sucrose stock solution is used to prepare in Buffer A 1X: i) 7\%-47\% linear sucrose gradient for analytical polysome profiling and ii) 5\%-25\% linear sucrose gradient for the ICs isolation.

6. Buffer B: $10 \mathrm{mM}$ HEPES-KOH pH 7.6, $50 \mathrm{mM} \mathrm{KAc,} 10 \mathrm{mM} \mathrm{NH}_{4} \mathrm{Cl}, 5 \mathrm{mM} \mathrm{Mg}(\mathrm{Ac})_{2}$, $2 \mathrm{mM}$ DTT. This buffer is used to resuspend pelleted isolated complexes for Cryo-EM studies.

7. $\left[\alpha-{ }^{32} \mathrm{P}\right]-\mathrm{GTP}(6000 \mathrm{Ci} / \mathrm{mmol})$.

Prepare all the solutions using ultrapure RNase free water (Milli-Q deionized water attaining a sensitivity of $18 \mathrm{M} \Omega-\mathrm{cm}$ at $25^{\circ} \mathrm{C}$ ). Filter them with $0.22 \mu \mathrm{m}$ membrane sterile syringe filter (SARSTED) and a $10 \mathrm{ml}$ syringe (see note 1$)$.

\subsection{Antibiotics and translation inhibitors}

1. Cycloheximide (Sigma-Aldrich) powder is dissolved in water. Stock solution of 10 $\mathrm{mg} / \mathrm{ml}$ can be stored at $-80^{\circ} \mathrm{C}$ for one month.

2. GMP-PNP (Sigma-Aldrich), powder is dissolved in water. Stock solution of $50 \mathrm{mM}$ is stored at $-80^{\circ} \mathrm{C}$.

\subsection{Instrument and accessories}

1. Gradient Master ${ }^{\mathrm{TM}}$ device (BioComp Instruments, Fredericton, Canada) is used to generate linear sucrose gradients.

2. Piston Gradient Fractionator ${ }^{\mathrm{TM}}$ implemented with Triax ${ }^{\mathrm{TM}}$ Flow Cell is used for precise fractionation of sucrose gradients from the top down. 
3. Beckman SW41 Ti Swinging-Bucket Rotor and Optima XE-90 ultracentrifuge.

4. Open-Top Polyclear ${ }^{\mathrm{TM}}$ Centrifuge Tubes (Seton scientific).

5. Sorvall-Hitachi S140AT fixed angle rotor and M150 SE ultracentrifuge.

6. NanoDrop ND-1000 Spectrophotometer (Thermo Fisher Scientific, Waltham, MA, USA) or equivalent.

7. Micro Bio-Spin ${ }^{\mathrm{TM}} 6$ Columns (Bio-Rad).

8. Refrigerated Centrifuge.

9. High-precision balance.

\section{Methods}

\section{1 mRNA transcription and capping}

The template for human $\beta$-globin mRNA transcription (494 nt; accession number BC007075) was generated by PCR amplification from a plasmid containing the gene, essentially as described in [27]. The PCR product was phenol-extracted and precipitated with ethanol. The purified PCR product $(5-8 \mu \mathrm{g})$ were directly used as templates for the in vitro transcription of $\beta$-globin mRNA using $0.2 \mathrm{mg} / \mathrm{ml}$ of T7 RNA polymerase in a $100 \mu \mathrm{l}$ volume of TMSDT buffer containing $5 \mathrm{mM}$ of each NTP and 40 units of human placenta RNase inhibitor (RNasin, Promega). The reaction was incubated at $37^{\circ} \mathrm{C}$ for $2 \mathrm{~h}$ followed by a further 1h in the presence of RNase-free DNase I (4 units, New England Biolabs) to degrade the PCR template. Transcription products were purified to homogeneity from abortive transcription or degradation products using denaturing polyacrylamide-urea gel electrophoresis (urea-PAGE) on $8 \%$ polyacrylamide/ $8 \mathrm{M}$ urea slab gels. After migration, the gel is removed from glass plates, RNA is visualized by UV shadowing on UV fluorescent TLC plate, and the band is cut from the acrylamide gel using a clean scalpel. The RNA is passively eluted at $4^{\circ} \mathrm{C}$ overnight by 
gently mixing in RNA Elution Buffer and then extracted by phenol/chloroform treatment, precipitated in ethanol, washed with $85 \%$ ethanol and vacuum-dried. The pure transcript was resuspended in ultrapure water, capped using the ScriptCap $\mathrm{m}^{7} \mathrm{G}$ Capping System (Epicenter) and stocked at $-20^{\circ} \mathrm{C}$. Radiolabeled transcripts were obtained by substituting the GTP from the capping kit with $\left[\alpha^{32} \mathrm{P}\right] \mathrm{GTP}$. Micro Bio-Spin ${ }^{\mathrm{TM}} 6$ Column is used to remove unincorporated GTP or $\left[\alpha^{32} \mathrm{P}\right] \mathrm{GTP}$ in case of a radiolabel mRNA.

\subsection{Linear sucrose gradient preparation}

$5 \%-25 \%$ linear sucrose density gradient centrifugation is used to isolate pure $\beta$ globin/48SIC directly from RRL incubated with $10 \mathrm{mM}$ (final concentration) GMP-PNP. To obtain a linear sucrose density gradient, the Gradient Master device (BioComp) is used with the 'SW41 Short Gradient' program and the corresponding range of sucrose percentage following the manufacturer's manual. The use of the Gradient Master ${ }^{\mathrm{TM}}$ device offers the great advantage of preparing 6 reproducible and identical linear gradients of $12.5 \mathrm{ml}$ (final volume) in one run. Tubes are cupped (short cups) and placed in a magnetic tube holder that adheres to the rotary steel plate on the instrument (see notes 2, 3 and 4). The percentage of sucrose used for linear gradients can be adjusted to optimize the separation of polysomal fractions according to the biological sample or experiment.

\section{3 $\beta$-globin/48SIC formation and isolation from sucrose gradient}

In order to stall functional intermediate initiation complexes, compounds that inhibits specific steps of the translation machinery assembly need to be used. As mentioned above, in the presence of GMP-PNP the GTPase eIF2 remains bound to the ribosome impairing subunits joining and thus blocking the ribosome assembly at the 48S late-stage. To identify on the gradient the peak corresponding to the $48 \mathrm{SIC}$, radiolabeled $\beta$-globin mRNA $(250,000 \mathrm{cpm}$ per 
gradient) is incubated with nuclease treated RRL in the presence of $10 \mathrm{mM}$ GMP-PNP as described in [31]. The reaction is fractionated on 5\%-25\% linear sucrose density gradient by centrifugation using SW41 Ti rotor, yielding optimal separation of the 48SIC late-stage particles from the $60 \mathrm{~S}$ ribosomal subunits, as detected on native agarose gel electrophoresis (Figure 2). Sample buffer components such as glycerol, sucrose and detergent can reduce specimen contrast in Cryo-EM. To completely remove sucrose, $\beta$-globin/48SIC containing fractions are pooled and the ribosomal complexes pelleted by centrifugation. The pellet is resuspended in Buffer B, which is suitable for both Cryo-EM and Mass Spectrometry analysis (Figure 2). The composition of the isolated $\beta$-globin/48SIC is determined by nano-liquid chromatography (LC) tandem mass spectrometry (MS/MS) helping the interpretation of the 3D density map obtained using Cryo-EM.

Grad-Cryo EM approach can be adapted to also isolate the 80SICs by incubating RRL with the $\beta$-globin mRNA in the presence of cycloheximide, instead of GMP-PNP.

\subsubsection{The experiment}

1. 5\%-25\% linear sucrose gradient should be prepared and stored at $4{ }^{\circ} \mathrm{C}$ at least two hours before loading of the sample.

2. Prior to stall late-stage $48 \mathrm{SIC}$, ribosomes need to be reactivated. Thus, nuclease-treated RRL (Promega) should be incubated for $5 \mathrm{~min}$ at $30^{\circ} \mathrm{C}$ in presence of a mixture of amino acids and then chilled on ice for 10 min. Amino acid mixture is provided with the Rabbit Reticulocyte Lysate System Kit to optimize translation.

3. Cycloheximide and hygromycin are thawed slowly on ice during ribosome activation step. 
4. $60 \mu \mathrm{l}$ of nuclease-treated RRL are incubate at $30^{\circ} \mathrm{C}$ in the presence of $10 \mathrm{mM}$ of GMP-PNP. After two minutes of incubation, $13 \mu \mathrm{g}$ of $\beta$-globin mRNA is added and the reaction mix is furthered incubated $5 \mathrm{~min}$ at $30^{\circ} \mathrm{C}$ and chilled on ice for $10 \mathrm{~min}$.

5. The reaction mix is layered ( $157 \mu$ l volume) onto $12,5 \mathrm{ml}$ of $5 \%-25 \%$ linear sucrose gradient and centrifugated at $37,000 \mathrm{rpm}$ for 4 hours and 37 minutes in a Beckman SW41 Ti Swinging-Bucket Rotor (see note 4).

6. The gradient is fractionated from the top down using BioComp Piston Gradient Fractionator $^{\mathrm{TM}}$ devise implemented with Triax ${ }^{\mathrm{TM}}$ Flow Cell. This system allows monitoring the $\mathrm{A}_{260}$ absorbance throughout the fractionation process (see notes 5-6).

7. An identical experiment is performed using 5 '-labelled capped $\beta$-globin mRNA to identify fractions containing $\beta$-globin/48SIC.

8. Once identified, the fractions are centrifugated at $108,000 \mathrm{rpm}$ for 2 hours at $4{ }^{\circ} \mathrm{C}$ in a Sorvall-Hitachi S140AT fixed angle rotor. Ribosome pellet is dissolved in buffer B, which is compatible for both Mass spectrometry and cryo-EM analysis (see note 7).

9. Composition of the obtained Cryo-EM 3D reconstruction of the purified $\beta$-globin/48SIC is confirmed by nanoLC MS/MS analysis.

Grad-CryoEM method yielded 2,106 pmoles of pure $\beta$-globin/48SIC from the incubation of 60 $\mu 1$ of RRL with $13 \mu \mathrm{g}$ (108 pmoles) of $\beta$-globin mRNA in the presence of $10 \mathrm{mM}$ of GMPPNP. $4 \mu \mathrm{l}$ of $\beta$-globin/48SIC concentrated $70 \mathrm{nM}$ were applied on 400 mesh holey carbon Quantifoil 2/2 grids (Quantifoil Micro Tools) to perform Cryo-EM analysis. The cryo-EM structure of the $\beta$-globin/48SIC at $5.86 \AA$ resolution [31] has shown the molecular details of the first decoding event on the start codon occurring at the end of the scanning process. eIF2/MettRNAi $^{\text {Met }}$ is present, while no density for eIF 1 could be observed, thus suggesting his dissociation from the complex upon start codon recognition, as confirmed by mass spectrometry 
analysis. Surprisingly, the 3D reconstruction has also shown an extra density located on the $40 \mathrm{~S}$ intersubunit face. Both, shape of the density and mass spectrometry data allowed assigning this density to ABCE1, an ATP-binding protein implicated in subunits disjoining after termination of translation [35]. This unexpected result demonstrates the importance of adopting methods for native complexes purification, but at the same time also indicates its limits. In fact, to unambiguously identify new factors when the obtained resolution of the structure is not enough to distinguish amino acid side chains, a deep characterization of the complex should be obtained by combining other techniques. A successful strategy has been attained by using immunolabeled Cryo-EM in combination with Grad-CryoEM [36].

\section{Notes}

1. All buffers used here are filtered using a $0.22 \mu \mathrm{m}$ membrane sterile syringe filter (SARSTED) to ensure buffer sterilization, and stored at $4{ }^{\circ} \mathrm{C}$. The buffer solutions are made fresh every week.

2. BioComb Gradient Master ${ }^{\mathrm{TM}}$ device is provided with two types of tube-cup. For our propose, we have used a short tube-cup which leave a $4 \mathrm{~mm}$ gap above the finished gradient.

3. Ones prepared, the gradients should be handled with care to avoid disturbance and stored at $4^{\circ} \mathrm{C}$ for at least $2 \mathrm{~h}$ before the layering of the sample.

4. Pay attention do not form air bubbles when the tube-cap is removed and during sample layering on the sucrose gradient, since it causes gradient perturbation throughout the centrifugation step.

5. Fractionate the gradient top down using Piston Gradient Fractionator ${ }^{\mathrm{TM}}$ connected to a fraction collector. Fast flow rates can reduce resolution and make it more difficult to 
collect precise fractions. For the isolation of $\beta$-globin/48SIC approximately $250 \mu \mathrm{L}$ per Eppendorf tube were collected using piston speed of $0.12 \mathrm{~mm} / \mathrm{sec}$.

6. In case several gradients should be fractionated, a washing step of the Piston Gradient Fractionator system is strongly suggested to avoid contamination of $60 \mathrm{~S}$ ribosomal subunit.

7. During the ultracentrifugation step, the ribosome complex precipitate forming an unstable pellet that should be handle carefully. Thus, the supernatant containing sucrose should be quickly and completely removed, avoiding the perturbation of the pellet.

\section{BIBLIOGRAPHY}

1. Sorensen, M.A., C.G. Kurland, and S. Pedersen, (1989) Codon usage determines translation rate in Escherichia coli. J Mol Biol. 207: p. 365-77

2. Wintermeyer, W., F. Peske, M. Beringer, K.B. Gromadski, A. Savelsbergh, and M.V. Rodnina, (2004) Mechanisms of elongation on the ribosome: dynamics of a macromolecular machine. Biochem Soc Trans. 32: p. 733-7

3. Lovmar, M. and M. Ehrenberg, (2006) Rate, accuracy and cost of ribosomes in bacterial cells. Biochimie. 88: p. 951-61

4. Rodnina, M.V., M. Beringer, and W. Wintermeyer, (2007) How ribosomes make peptide bonds. Trends Biochem Sci. 32: p. 20-6

5. Zaher, H.S. and R. Green, (2009) Fidelity at the molecular level: lessons from protein synthesis. Cell. 136: p. 746-62

6. Kennell, D. and H. Riezman, (1977) Transcription and translation initiation frequencies of the Escherichia coli lac operon. J Mol Biol. 114: p. 1-21 
7. Gold, L., (1988) Posttranscriptional regulatory mechanisms in Escherichia coli. Annu Rev Biochem. 57: p. 199-233

8. Hinnebusch, A.G., (2011) Molecular mechanism of scanning and start codon selection in eukaryotes. Microbiol Mol Biol Rev. 75: p. 434-67, first page of table of contents

9. Jackson, R.J., C.U. Hellen, and T.V. Pestova, (2010) The mechanism of eukaryotic translation initiation and principles of its regulation. Nat Rev Mol Cell Biol. 11: p. $113-27$

10. Parsyan, A., Y. Svitkin, D. Shahbazian, C. Gkogkas, P. Lasko, W.C. Merrick, and N. Sonenberg, (2011) mRNA helicases: the tacticians of translational control. Nat Rev Mol Cell Biol. 12: p. 235-45

11. Sonenberg, N. and A.G. Hinnebusch, (2009) Regulation of translation initiation in eukaryotes: mechanisms and biological targets. Cell. 136: p. 731-45

12. Aylett, C.H. and N. Ban, (2017) Eukaryotic aspects of translation initiation brought into focus. Philos Trans R Soc Lond B Biol Sci. 372

13. Spahn, C.M., J.S. Kieft, R.A. Grassucci, P.A. Penczek, K. Zhou, J.A. Doudna, and J. Frank, (2001) Hepatitis C virus IRES RNA-induced changes in the conformation of the 40s ribosomal subunit. Science. 291: p. 1959-62

14. Spahn, C.M., E. Jan, A. Mulder, R.A. Grassucci, P. Sarnow, and J. Frank, (2004) Cryo-EM visualization of a viral internal ribosome entry site bound to human ribosomes: the IRES functions as an RNA-based translation factor. Cell. 118: p. 46575

15. Hashem, Y., A. des Georges, V. Dhote, R. Langlois, H.Y. Liao, R.A. Grassucci, T.V. Pestova, C.U. Hellen, and J. Frank, (2013) Hepatitis-C-virus-like internal ribosome entry sites displace eIF3 to gain access to the 40S subunit. Nature. 503: p. 539-43 
16. Martin, F., J.F. Menetret, A. Simonetti, A.G. Myasnikov, Q. Vicens, L. Prongidi-Fix, S.K. Natchiar, B.P. Klaholz, and G. Eriani, (2016) Ribosomal 18S rRNA base pairs with mRNA during eukaryotic translation initiation. Nat Commun. 7: p. 12622

17. Martin, F., S. Barends, S. Jaeger, L. Schaeffer, L. Prongidi-Fix, and G. Eriani, (2011) Cap-assisted internal initiation of translation of histone H4. Mol Cell. 41: p. 197-209

18. Dubochet, J., J. Lepault, R. Freeman, J.A. Berriman, and J.-C. Homo, (1982) Electron microscopy of frozen water and aqueous solutions. Journal of Microscopy. 128: p. 219-237

19. Gilbert, R.J., Y. Gordiyenko, T. von der Haar, A.F. Sonnen, G. Hofmann, M. Nardelli, D.I. Stuart, and J.E. McCarthy, (2007) Reconfiguration of yeast 40S ribosomal subunit domains by the translation initiation multifactor complex. Proc Natl Acad Sci U S A. 104: p. $5788-93$

20. Passmore, L.A., T.M. Schmeing, D. Maag, D.J. Applefield, M.G. Acker, M.A. Algire, J.R. Lorsch, and V. Ramakrishnan, (2007) The eukaryotic translation initiation factors eIF1 and eIF1A induce an open conformation of the 40S ribosome. Mol Cell. 26: $\mathrm{p}$. $41-50$

21. Llacer, J.L., T. Hussain, L. Marler, C.E. Aitken, A. Thakur, J.R. Lorsch, A.G. Hinnebusch, and V. Ramakrishnan, (2015) Conformational Differences between Open and Closed States of the Eukaryotic Translation Initiation Complex. Mol Cell. 59: p. $399-412$

22. Hashem, Y., A. des Georges, V. Dhote, R. Langlois, H.Y. Liao, R.A. Grassucci, C.U. Hellen, T.V. Pestova, and J. Frank, (2013) Structure of the mammalian ribosomal 43S preinitiation complex bound to the scanning factor DHX29. Cell. 153: p. 1108-19

23. Hussain, T., J.L. Llacer, I.S. Fernandez, A. Munoz, P. Martin-Marcos, C.G. Savva, J.R. Lorsch, A.G. Hinnebusch, and V. Ramakrishnan, (2014) Structural changes 
enable start codon recognition by the eukaryotic translation initiation complex. Cell. 159: p. 597-607

24. des Georges, A., V. Dhote, L. Kuhn, C.U. Hellen, T.V. Pestova, J. Frank, and Y. Hashem, (2015) Structure of mammalian eIF3 in the context of the 43S preinitiation complex. Nature. 525: p. 491-5

25. Aylett, C.H., D. Boehringer, J.P. Erzberger, T. Schaefer, and N. Ban, (2015) Structure of a yeast 40S-eIF1-eIF1A-eIF3-eIF3j initiation complex. Nat Struct Mol Biol. 22: p. $269-71$

26. Prongidi-Fix, L., L. Schaeffer, A. Simonetti, S. Barends, J.F. Menetret, B.P. Klaholz, G. Eriani, and F. Martin, (2013) Rapid purification of ribosomal particles assembled on histone H4 mRNA: a new method based on mRNA-DNA chimaeras. Biochem J. 449: p. $719-28$

27. Chicher, J., A. Simonetti, L. Kuhn, L. Schaeffer, P. Hammann, G. Eriani, and F. Martin, (2015) Purification of mRNA-programmed translation initiation complexes suitable for mass spectrometry analysis. Proteomics. 15: p. 2417-25

28. Garreau de Loubresse, N., I. Prokhorova, W. Holtkamp, M.V. Rodnina, G. Yusupova, and M. Yusupov, (2014) Structural basis for the inhibition of the eukaryotic ribosome. Nature. 513: p. 517-22

29. Schneider-Poetsch, T., J. Ju, D.E. Eyler, Y. Dang, S. Bhat, W.C. Merrick, R. Green, B. Shen, and J.O. Liu, (2010) Inhibition of eukaryotic translation elongation by cycloheximide and lactimidomycin. Nat Chem Biol. 6: p. 209-217

30. Anthony, D.D. and W.C. Merrick, (1992) Analysis of $40 \mathrm{~S}$ and $80 \mathrm{~S}$ complexes with mRNA as measured by sucrose density gradients and primer extension inhibition. $\mathrm{J}$ Biol Chem. 267: p. 1554-62 
31. Simonetti, A., J. Brito Querido, A.G. Myasnikov, E. Mancera-Martinez, A. Renaud, L. Kuhn, and Y. Hashem, (2016) eIF3 Peripheral Subunits Rearrangement after mRNA Binding and Start-Codon Recognition. Mol Cell. 63: p. 206-17

32. de la Rosa-Trevin, J.M., A. Quintana, L. Del Cano, A. Zaldivar, I. Foche, J. Gutierrez, J. Gomez-Blanco, J. Burguet-Castell, J. Cuenca-Alba, V. Abrishami, J. Vargas, J. Oton, G. Sharov, J.L. Vilas, J. Navas, P. Conesa, M. Kazemi, R. Marabini, C.O. Sorzano, and J.M. Carazo, (2016) Scipion: A software framework toward integration, reproducibility and validation in 3D electron microscopy. J Struct Biol. 195: p. 93-9

33. Scheres, S.H., (2012) RELION: implementation of a Bayesian approach to cryo-EM structure determination. Journal of structural biology. 180: p. 519-530

34. Grigorieff, N., (2016) Frealign: An Exploratory Tool for Single-Particle Cryo-EM. Methods Enzymol. 579: p. 191-226

35. Mancera-Martinez, E., J. Brito Querido, L.S. Valasek, A. Simonetti, and Y. Hashem, (2017) ABCE1: A special factor that orchestrates translation at the crossroad between recycling and initiation. RNA Biol. 14: p. 1279-1285

36. Brito Querido, J., E. Mancera-Martinez, Q. Vicens, A. Bochler, J. Chicher, A. Simonetti, and Y. Hashem, (2017) The cryo-EM Structure of a Novel 40S Kinetoplastid-Specific Ribosomal Protein. Structure. 25: p. 1785-1794 e3 


\section{FIGURES LEGENDS}

Figure 1. Grad-CryoEM strategy to isolate $48 \mathrm{~S}$ and $80 \mathrm{~S}$ initiation complexes. The initiation complexes are stalled on the start codon of $\beta$-globin mRNA from Rabbit Reticulocyte Lysate (RRL), in presence of different translation initiation inhibitors, GMP-PNP for the 48SIC and cycloheximide for the 80 SIC. $7 \%-47 \%$ sucrose gradient analysis of the initiation complexes is used to monitor the formation of initiation complexes using $\mathrm{P}^{32}$ radio-labeled capped $\beta$-globin mRNA. In absence of any inhibitor (blue line) polysomes are detectable, while in presence of cycloheximide (green line) or GMP-PNP (red line) could be observed a consequent accumulation of $80 \mathrm{~S}$ monomer ribosomes and $48 \mathrm{SIC}$, respectively.

Figure 2. 48SIC isolation, factors composition and structure determination. $\beta$-globin mRNA is incubated with RRL in presence of GMP-PNP to accumulate 48SIC. The RRL is fractionated on a $5 \%-25 \%$ sucrose gradient to isolate stalled $48 \mathrm{SIC}$, monitored using radioactive capped $\beta$-globin mRNA (orange line). Ribosome localization is confirmed by optical density at $260 \mathrm{~nm}$ (green dashed line). After isolation, native agarose gel electrophoresis analysis is performed to asses the purity of the complex. The isolated $\beta$-globin-48SIC is then analyzed by nano-LC-MS/MS to get insights on its composition and by Cryo-EM to determine its structure (EMD-8190 and PDB- 5K0Y [31]). 


\section{Figure 1}

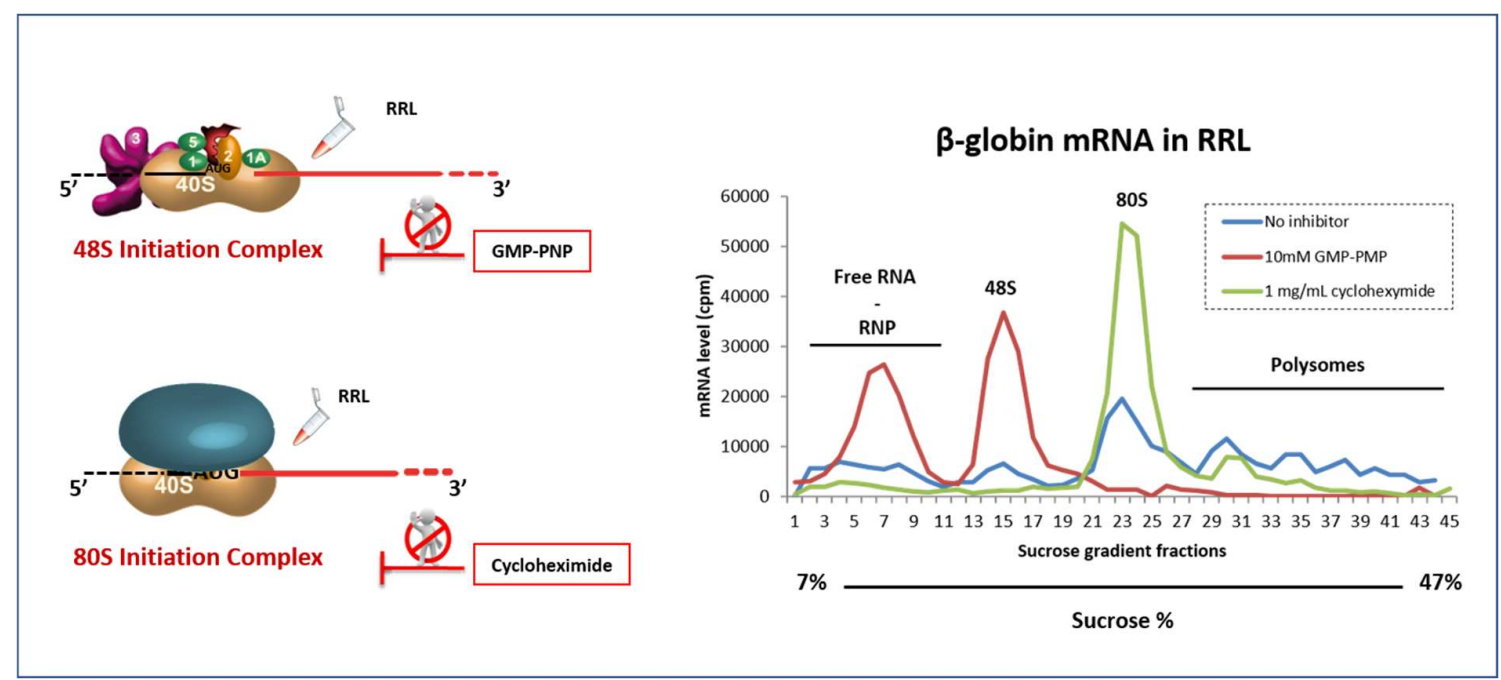


Figure 2

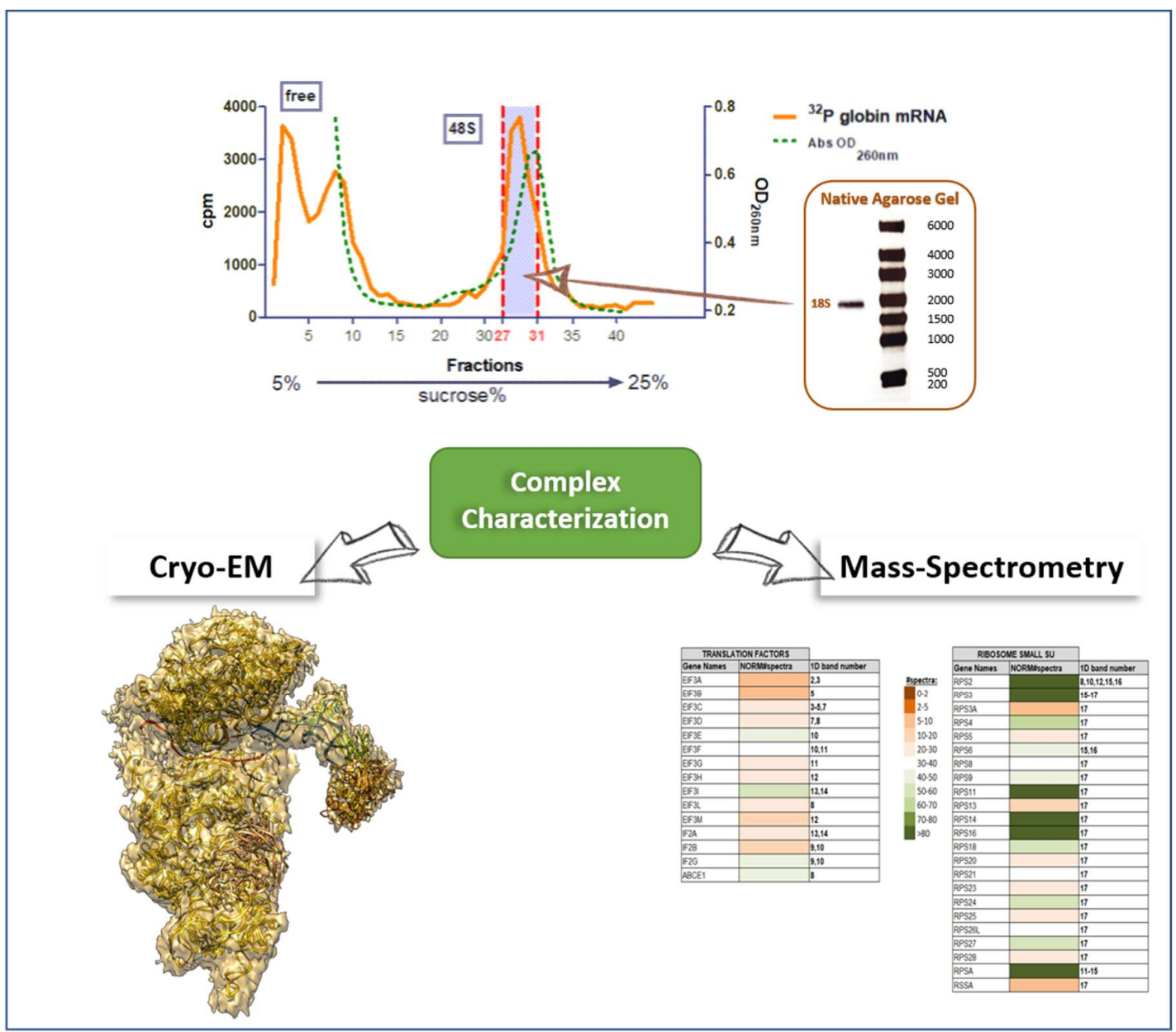

